Amanecer paisano y dormir soldado... Resistencias frente al reclutamiento y el servicio militar en la ciudad de México (1824-1858)

\author{
Amanecer paisano y dormir soldado... Reactions \\ against military recruitment and military \\ service in Mexico City (1824-1858)
}

\section{Claudia Ceja Andrade}

\section{Resumen}

Palabras clave

\section{Abstract}

Keywords

\begin{abstract}
Universidad Autónoma de Querétaro, Querétaro, México
Correo electrónico: ceac45@hotmail.com

Doctora en Historia por El Colegio de México. Es profesora investigadora de la Universidad Autónoma de Querétaro desde el 2014. Entre sus últimas publicaciones destaca "Una mirada a las fuerzas armadas de la ciudad de México a través de las hojas de filiación y los procesos militares, 1824-1859", en Tzintzun. Revista de Estudios Históricos, agosto-diciembre 2018.
\end{abstract}

A través de sumarios militares por los delitos de abandono de guardia y deserción, hojas de filiación, prensa y demás fuentes, este artículo reflexiona sobre algunas de las respuestas que la población masculina hizo para evadir el reclutamiento y el servicio militar durante las primeras décadas del siglo xIx. Se dará cuenta de las ideas y creencias que se tenían sobre la conscripción, especialmente, la forzada. El objetivo específico es mostrar las tácticas de resistencia de reclutas y soldados, y reflexionar sobre estos mecanismos implementados “desde abajo" que dieron forma a la dinámica militar.

Reclutamiento, ejército, resistencias, ciudad de México; siglo XIX Through military tries for the crimes of abandonment of guard and desertion, military records, press and other sources, this article reflects on some of the responses that the male population carried out to evade both the recruitment as military service during the first decades of the 19th century. The article realizes the ideas and beliefs that were held about conscription, especially about the forced. The goal is demonstrate the type of resistance tactics of recruits and soldiers, and reflect on the fact that mechanisms "from below" shaped military dynamics.

Recruitment, army, resistances, Mexico City, 19th century
Recibido/Received

Aprobado/Approved
31 de enero de 2018

28 de mayo de 2018 


\title{
Amanecer paisano y dormir soldado... Resistencias frente al reclutamiento y el servicio militar en la ciudad de México $(1824-1858)^{1}$
}

\author{
Claudia Ceja Andrade
}

\section{Introducción}

El proceso de conformación de las fuerzas armadas mexicanas después de las guerras de independencia fue una historia compleja y llena de vicisitudes que mucho dependió de los gobiernos en turno, los pronunciamientos militares, las guerras civiles, la relación tensa entre los poderes locales y centrales, etc. Estas aristas han sido estudiadas con detenimiento para dar cuenta de la evolución del ejército como institución, destacando además su relevancia en la consolidación del Estado mexicano. ${ }^{2}$

El papel del ejército no sólo se ha revisado a partir de sus relaciones con el Estado sino también se ha puesto énfasis en los vínculos con los gobiernos locales y municipales, revelando el fortalecimiento de las milicias y el poder de los caudillos, además se subrayó la actuación y experiencia de estos últimos como oficiales pues no sólo tenían a su cargo la movilización de tropas, sino que eran quienes mantenían un diálogo permanente entre el gobierno central y las regiones. ${ }^{3}$ Acerca de las formas y tipos de reclutamiento José Antonio Serrano Ortega analizó el impacto del reclutamiento en términos políticos, militares y

${ }^{1}$ Una primera versión de este artículo fue discutida en junio del 2017 en el Seminario de Historia Sociocultural de la Transgresión dirigido por Elisa Speckman y Martha Santillán. Agradezco a todos los integrantes del seminario sus críticas y comentarios; en la medida de lo posible traté de incluir sus sugerencias.

${ }^{2}$ La bibliografía sobre el particular es amplia, destaco sólo algunos: Kahle (1997), Vázquez (2005), Vázquez (1984), Ortiz (2005), de este mismo autor véanse también (1988, 1991, 1999 y 2007). También Chust y Marchena (2007).

3 Serrano (1993) y (2001), Ortiz (2007) y (1988), Hernández Chávez (2007), Hernández López (2001 y 2006). 
sociales toda vez que los estados, en su mayoría, destinaban a gente poco apta para las labores castrenses; ${ }^{4}$ en ese sentido, la condición forzosa del servicio de armas fue continua y ello mismo hizo que la deserción fuera una realidad cotidiana y permanente. ${ }^{5}$

Ya se ha mostrado una compleja problemática en torno a los desertores, desde la utilización de éstos -cuando eran capturados- como cuerpos de reemplazos en las emergencias armadas y su amnistía; hasta las formas usadas para evadir la justicia castrense, así como las disputas entre concejales y mandos del ejército a la hora de juzgarlos. ${ }^{6}$

A pesar de esos esfuerzos loables, todavía se sabe poco acerca de la gente que integraba dichas corporaciones, sus experiencias y las relaciones creadas en estos espacios. ${ }^{7}$ A partir de 123 sumarios por los delitos de abandono de guardia y deserción (de los cuales sólo 111 contaban con la hoja de filiación) y demás fuentes primarias (memorias del ministerio de guerra, prensa, diarios, etc.), en el presente trabajo se reflexionará sobre algunas de las respuestas que la población masculina llevó a cabo para evadir tanto el reclutamiento como el servicio militar durante las primeras décadas del México republicano. ${ }^{8}$

Los expedientes que cuentan con hoja de filiación nos permiten saber con precisión algunos datos de los reclutas, puesto que servían para registrar a los miembros de las fuerzas armadas a partir de una detallada descripción física, su lugar de origen, oficio, procedencia, actividad productiva, si sabían leer o escribir, padres, entre otros. En éstas podemos encontrar el rango y cuando sentaban plaza, a veces también los años de servicio y por qué autoridad habían sido remitidos. El delito también viene estipulado, en ocasiones con cierto detalle, y algunas contienen breves referencias sobre los antecedentes del sujeto:

${ }^{4}$ Serrano (1993 y 1996).

${ }^{5}$ Vanesa Teitelbaum ha explicado que la falta de oportunidades laborales ocasionada por la contracción económica de las primeras décadas del siglo xix provocó que gente subempleada o desempleada fuera catalogada como vaga y enviada al servicio como forma de castigo y control social. Teitelbaum (2008 y 2001).

${ }^{6}$ Cacho (2013).

7 Sobre la composición social del ejército a mediados del siglo xIX véase Pérez (2008).

${ }^{8}$ Un primer acercamiento a este tipo de transgresiones aparece en Ceja (2018). 
su comportamiento en la institución, sus ascensos, entre otras cosas que los superiores consideraban de importancia.

Los expedientes de estos juicios (como muchos otros del siglo xIx) igualmente contienen una rica información sobre las costumbres de la época porque refieren la forma como procedieron los infractores, sus expresiones y las referencias de terceros, costumbres, lenguaje, etcétera. En suma, constituyen una rica fuente que nos muestra las dinámicas de la vida social dentro y fuera de los cuarteles de estos infractores pertenecientes a las fuerzas armadas.

Posiblemente se pensará que la muestra de 123 procesos militares no puede ser representativa de fenómenos generalizados en las fuerzas armadas, no obstante debemos considerar que el estudio de estos conflictos en pequeña escala revela tensiones latentes dadas las contradicciones de la propia institución. ${ }^{9}$ Estos fenómenos ya fueran generales o excepcionales entre la población castrense, son dignos de analizarse pues permiten comprender mejor el impacto de sus prácticas en la dinámica institucional, así como el proceso histórico del ejército desde la óptica de lo social.

\section{El contexto}

¿Pero por qué fue tan compleja la conformación de las fuerzas armadas? De entrada, debemos considerar que el México independiente nació con una gran variedad de contingentes cuya brevedad e integración con otros cuerpos armados fueron constantes. ${ }^{10}$ Si bien prevaleció el anhelo novohispano de conformar un ejército profesional y disciplinado, la tendencia a reclutar a los elementos nocivos de la sociedad como los vagos y mendigos, así como las prácticas clientelares rápidamente pervirtieron al naciente ejército mexicano. ${ }^{11}$

Dentro de los dos proyectos de nación aquellos que apoyaban el proyecto federalista favorecieron las milicias y el fortalecimiento de los estados, mientras

9 Tal y como advierte Peter Burke, poner el énfasis en la desviación de la norma nos acerca a las "tensiones sociales presentes todo el tiempo pero que sólo en ocasiones se hacen visibles”, Burke (1997, p. 55, 56).

${ }^{10}$ Ortiz (2007, p. 298).

${ }^{11}$ Ortiz (2005), Cacho (2013). 
que los otros buscaron consolidar al Estado mexicano y al ejército federal. De esta forma el activo (o milicia activa) fue concebido como un ejército de reserva habilitado para un distrito fijo o una provincia; sin embargo, los requerimientos propios de los gobiernos locales hicieron que muchas veces lo usaran como ejército permanente. Ortiz Escamilla señala que las milicias terminaron bajo las órdenes de los ayuntamientos de 1820 a 1825 y a partir de 1827 de las gubernaturas estatales (a través de las comandancias militares de los estados), a diferencia del ejército permanente que quedó subordinado al ejecutivo federal. ${ }^{12}$ De esta forma se constata que para un Estado débil,${ }^{13}$ necesitado constantemente de recursos y del respaldo castrense, fueron inevitables esos acuerdos y negociaciones con algunos prominentes oficiales que vieron fortalecido su poder local y personal. ${ }^{14}$

La guerra con Estados Unidos en 1846 motivó la creación de la Guardia Nacional, que fue reglamentada hasta 1848 , a partir de las milicias organizadas por los ayuntamientos. Este modelo buscó por un lado controlar la variedad de milicias, pero también fue usado para restringir la preeminencia y privilegios del ejército. ${ }^{15}$ La idea de la ciudadanía armada y organizada en milicias fue tomada de la Revolución Francesa, pero en México se adaptó a una realidad más beligerante. Los milicianos compartían su carácter ciudadano con el militar y en varias ocasiones buscaron restringirles el fuero y controlarlos integrándolos a las milicias provinciales o subordinándolos al ejecutivo estatal. La reducción o aumento de éstas dependió de criterios político-estratégicos y económicos; mientras que durante la dictadura de Santa Anna fueron suprimidas $(1853-1855){ }^{16}$

${ }^{12}$ Ortiz (2007, p. 296).

${ }^{13}$ Serrano (2001), Ortiz (2007), Hernández Chávez (2007).

14 Vázquez (2005).

${ }^{15}$ Hernández López (2009, p. 39, 40). Manuel Chust Calero es quien ha escrito sobre la variedad y diferencia de las milicias (nacional, cívica, guardia nacional), Chust (2005). También véase Ortiz (2007).

${ }^{16}$ Hernández López $(2008$, p. 5, 6). Manuel Chust señala que las primeras milicias cívicas del México independiente convocaron a los ciudadanos que poseían cierto nivel de renta o propiedad, pero ante la renuencia y falta de cooperación de éstos, en el reglamento de 1827 se incluyó a todos los mexicanos favoreciendo el reclutamiento de artesanos, empleados y traba- 
Conrado Hernández opina que el ejército por su parte mantuvo cierta continuidad en su estructura organizativa, no obstante los cambios y depuraciones emprendidas en las diferentes administraciones; así mantuvo la vigencia de la ordenanza, el fuero, además de la función judicial en su capacidad de conocer causas militares y civiles, dado que los cambios fueron más cuantitativos que cualitativos. ${ }^{17}$ Todo lo anterior permitió que "convivieran militares de tres generaciones que, a pesar de sus diferencias de edad y experiencia, terminaron unidas de una u otra manera con alguna de las dos causas políticas que se confrontaron entre 1855 y $1860 " .{ }^{18}$ Por su lado Josefina Zoraida Vázquez refiere que el ejército estaba formado por todas las facciones políticas, por lo cual distó de ser un ente monolítico, y solamente después de la independencia de Texas los comandantes generales asumieron la gubernatura de varios departamentos y actuaron como inspectores de Hacienda. ${ }^{19}$

Durante el periodo de estudio podemos constatar que permanecieron los métodos de reclutamiento forzoso para la tropa creando soldados mal alistados, con un adiestramiento deficiente y grandes resistencias. Muchos de estos soldados desertaban, otros aprendían a vivir yendo y viniendo de las filas castrenses, y otros más se adaptaban llevando consigo mujeres e hijos. ${ }^{20}$ También hubo quienes buscaron cumplir con la obligación del servicio refugiándose en la milicia cívica -luego en la Guardia Nacional- con el fin de permanecer cerca de sus poblaciones. ${ }^{21}$

jadores. Como la resistencia prevalecía, las autoridades locales llegaron a valerse del reclutamiento forzoso como el ejército. Chust (2005, p. 182, 183).

${ }_{17}$ Hernández López $(2007$, p. 38, 39).

${ }^{18}$ Hernández López (2007, p. 38, 39).

${ }^{19}$ Así también sostiene que el ejército favoreció la inestabilidad mediante los pronunciamientos, pero muchos estuvieron auspiciados por civiles (comerciantes usureros, extranjeros, cosecheros de tabaco y algodón o cónsules comerciantes extranjeros). Vázquez (2005, p. 220, 221).

${ }^{20}$ Ceja (2103 y 2015).

${ }^{21}$ Chust sostiene que los cívicos usaron el alistamiento para sustraerse de las levas y los sorteos de la milicia provincial o activa; sin embargo y a pesar de las constancias emitidas por los ayuntamientos (de pertenecer a la milicia cívica) y la exigencia de fuero para quedar excluidos del ejército, fueron levantados por la leva. Finalmente se facultó su inclusión en los sorteos de las milicias provinciales por el decreto del 6 de octubre de 1824. Chust $(2005$, p. 183, 184). 
Y no fueron pocas las confrontaciones entre los milicianos y los miembros del ejército, o entre éstos y los ayuntamientos que organizaban a los cívicos; del mismo modo que entre las autoridades estatales y federales. Lo cierto es que la mayoría de todos ellos, milicianos y soldados del ejército, tuvieron en algún momento de su vida una o más deserciones y por ello quedaron registradas en las hojas de filiación (que lograron conservarse) de estos procesos por deserción o abandono de guardia.

Ahora bien desde la Constitución de 1824, así como las Bases Constitucionales de 1836 y las Bases Orgánicas de 1843, se estipuló que los estados debían cooperar con el gobierno brindando reemplazos para el ejército permanente mediante los sorteos. ${ }^{22}$ Sin embargo, las leyes contra los vagos y mal entretenidos fortalecieron la determinación de los ayuntamientos de reclutar reemplazos mediante las levas. ${ }^{23}$ Desde épocas tempranas los munícipes fueron acusados de no cooperar con las autoridades siendo omisos en sus responsabilidades para realizar los sorteos, capturar a los desertores, denunciarlos e incluso fueron acusados de protegerlos. ${ }^{24}$

\section{Algunas impresiones sobre el reclutamiento}

Los cronistas de la época, como Bustamante, constantemente referían la realidad vivida entre la población acerca de los métodos de reclutamiento:

Pero entre nosotros, repitiendo las voces de libertad y de constitución, a presencia de los encargados de hacerla cumplir, ni se espera ni se pide ley, ni generosidad, ni escrupulosidad, ni excepciones ni audiencia, ni otra cosa que amanecer paisano y dormir soldado o marinero; despertar vecino de México, y anochecer siéndolo de Veracruz o Tampico [...] amanecer sin crimen o sin prue-

${ }^{22}$ Artículo 50, fracc. XVIII (1824); Tercera Ley Constitucional, art. 44, fracc. v (1836); art. 66, fracc. v (1843); apud Serrano, (1993, p. 15). El decreto de 1839 y la ley de 1844 se comprendían a los varones entre 18 y 40 años con oficio conocido. Cabe señalar que la Constitución de 1836 prohibió las milicias cívicas.

${ }^{23}$ Particularmente importante fue la formación del Tribunal de vagos de la ciudad de México en 1828 y su reformulación en 1845. Véase Aillón (2001).

${ }^{24}$ Cacho (2013, p. 39-44), Chust (2005, p. 182, 183). 
bas de él, y anochecer con una partida que recita las notas de ladrón, mal entretenido u homicida! ${ }^{25}$

Por su parte el síndico segundo del Ayuntamiento de la ciudad Juan Rodríguez de San Miguel, exponía al presidente de la república el grave problema que la población padecía por "la horrorosa leva, reclutamiento o toma de ciudadanos", pues:

Metidos de improviso entre esbirros, son conducidos a recibir ante autoridades políticas la sentencia de muerte disfrazada, bajo el nombre de consignación de la marina, consignación a las armas; y todo sin mediación de un juez, sin su menor audiencia, en un acto clandestino insolente, sin tiempo de defensa, sin audiencia de derechos, sin admisión de excepciones, y sin justificación de causas. ${ }^{26}$

Así en México durante buena parte del siglo xIx los pronunciamientos, guerras civiles e intervenciones extranjeras fueron moneda corriente y trajeron como resultado la necesidad casi permanente de efectivos para el ejército. El sorteo y la leva fueron dos métodos de alistamiento forzoso, pero en el primero se pretendía reclutar a varones entre 18 y 40 o 50 años (según el caso), a partir de los padrones realizados por los ayuntamientos entre sujetos "útiles" de la sociedad; en cambio la leva aplicaba a todos aquellos detenidos y juzgados como vagos, ebrios y mal entretenidos, cuya pena era compurgar años en el ejército como reemplazos. A través del sistema de reclutamiento las autoridades buscaban gente con un perfil deseable para cubrir las bajas por retiro (licenciamiento), deserción o muerte. ${ }^{27}$ Sin embargo, el reclutamiento a través del sorteo

\footnotetext{
25 “Domingo 8 de noviembre de 1840", Bustamante (2003).

26 “Representación dirigida al Excmo. Sr. Presidente de la República”, en El Cosmopolita, 26 de septiembre de 1838.

27 "Ley de 4 de noviembre de 1848 sobre el arreglo del ejército y disposiciones reglamentarias que dictó el Gobierno para su cumplimiento", Apéndice al tomo primero de la recopilación de leyes, decretos, circulares, reglamentos y disposiciones expedidos por la Secretaria de Guerra y Marina, p. 163.
} 
difícilmente se pudo poner en práctica y de lo que más echaron mano las autoridades fueron de las levas. ${ }^{28}$

La literatura de la época - prensa, diarios, memorias, reportes médicos y militares- da constancia de que cientos de hombres eran capturados en las calles de la ciudad para ser destinados a las fuerzas armadas. En estos escritos se advierte el continuo abuso de autoridad combinado con formas de coerción que dejaban de lado la idea de la persuasión a la hora del enganche. ${ }^{29}$ La prensa denunciaba cómo la leva era perjudicial para la sociedad pues desintegraba familias y vulneraba a la clase más miserable. El Cosmopolita, por ejemplo, señalaba:

En estos días los agentes del gobierno, han cogido de leva a muchos artesanos de honradez, que se habían alistado para servir en clase de defensores de la patria; lo que ha ocurrido a causa de la leva, ha aumentado el disgusto de los mexicanos, es sensible que las autoridades desacrediten la causa que deben defender, llevando amarrados a los que han de batirse con los franceses; despopularizar una causa tan nacional, es materia de responsabilidad. ${ }^{30}$

Dos años más tarde Madame Calderón de la Barca también expresaba su sentir al comentar la tristeza que estos hombres causaban al verlos encadenados hacia los cuarteles junto a mujeres e hijos quienes, en total desamparo, no tenían

${ }^{28}$ Para evitar el ingreso de criminales, vagos y gente con alguna discapacidad, el Ministerio de Guerra recomendó que el alistamiento fuera por sorteo pues sólo se enrolarían aquellos interesados. Memoria (1835, p. 13-16). Para 1839, se emitió el sorteo general para reemplazar las bajas del ejército", Dublán y Lozano, (1876, t. 3, p. 582-589). Esta clase de enganche corría a cargo de una comisión militar que a su vez requería del apoyo de las autoridades locales, pues era necesario levantar un padrón en el que se registraban los datos personales y laborales de los futuros conscriptos.

29 La bandera de recluta estaba conformada por oficiales y algunos soldados, éstos últimos tenían como misión persuadir a los hombres del pueblo o comunidad sobre los beneficios que adquirían, “la mejora que ha tenido el sueldo, y todo cuanto sea conveniente a inclinarlos, sin violencia ni dolo, a que voluntariamente adopten la carrera militar.", en "Reglamento de la ley de 4 de noviembre de 1848", en Apéndice al tomo primero (s/f: 166)

${ }^{30}$ El Cosmopolita, 22 de diciembre de 1838. 
más remedio que seguirlos. ${ }^{31}$ De igual modo, en noviembre de 1840, Carlos María de Bustamante declaraba:

Hoy a las once y media salió para Veracruz de Santo Domingo una cuerda de ciento cincuenta hombres tomados de leva, y ya vestidos de soldado, la cual se regresó al mismo convento a poco de haber salido. Fue innumerable el concurso de gentes que se presentó a verla salir, y todos murmuraban de esta disposición del gobierno. ${ }^{32}$

El periódico El Siglo XIX aseguraba que para narrar los inconvenientes del "sistema actual de reclutas" tendría que agotar toda la tinta de su pluma porque de no ser así:

Sería borrosa la descripción de los ciudadanos que hoy por desgracia se destinan a servir a las armas; amarrados, metidos en una cárcel, paseados como facinerosos, y luego sentenciados a servir con hambre y desnudez por toda la vida, porque en México nunca se encuentra un soldado ajustado ni cumplido. ${ }^{33}$

Las ideas y creencias sobre el reclutamiento forzoso y sus efectos nocivos prevalecieron hasta bien entrado el siglo XIX. ${ }^{34}$ Para la década de 1870 el médico

${ }^{31}$ Costeloe (2000, p. 22)

32 "Domingo 8 de noviembre de 1840", Bustamante, Diario histórico.

33 “Remitidos. El ejército", en El Siglo XIX, 13 de septiembre de 1844. En algunos repositorios como el Archivo Histórico de la Ciudad de México, el Archivo General de la Nación así como en el Archivo Histórico de la Suprema Corte de Justicia de la Nación encontramos varias cartas de familiares solicitando indulto y denunciando las arbitrariedades en contra de sus familiares. Véase la carta de Ana G. Pérez, abuela del soldado desertor Martín Ortiz quien murió a causa de los golpes que le dio la comisión encargada de aprehender desertores. "Averiguación contra el cabo del Batallón de Nacionales de la Libertad, Teófilo Ponce, acusado de haber herido gravemente a Martín Ortiz la mañana del 19 de febrero de 1847", en Archivo General de la Nación (en adelante AGN), Archivo de Guerra, v. 34, exp. 277.

34 Las denuncias en la prensa continuaron por varios años. Véanse, por citar algunos casos, los siguientes: el Diario de Avisos exponía que "una comisión de leva, no contenta con hacer teatro de sus proezas, condenadas por la ley, las calles de este capital, sale fuera de garitas en los caminos recluta a trabajadores y demás individuos con quienes por desgracia se tropieza", en Diario de Avisos, 11 de junio de 1857. La Sociedad revelaba que a las cinco y media de la 
Agustín García escribía que el reclutamiento era impopular porque, si se realizaba en las ciudades recaía siempre sobre el "artesano, el trabajador, los mozos domésticos, y los hombres que salen en busca de trabajo...”, si se verificaba en el campo se incorporaba a la "raza indígena, [...] el pastor, el jornalero, el arriero..." a decir del galeno, la clase menos corrompida, "pero suficientemente ignorante para corromperse con facilidad". ${ }^{35}$

Así pues y a decir del coronel Manuel Balbontín -quien estaba a favor del sorteo y no de la leva como forma de reclutamiento- pedía cierta prudencia sobre cómo y cuándo poner dicho método en práctica. Para él únicamente se debía utilizar cuando existieran bajas naturales, y de ninguna manera podía ser el medio de reemplazamiento general ya que el tipo de gente que llegaba sólo degradaba a la corporación..$^{36}$

Aunque hombres como el ministro de Guerra, José Antonio Facio, denunciaba en 1831 que la gente tomada de leva perjudicaba al ejército pues en las compañías siempre faltaban hombres y los que estaban eran poco profesionales, ${ }^{37}$ y para 1835 el ministro José María Tornel informaba que los hombres enviados por los gobiernos locales habían sido remitidos a las fronteras, costas y lugares de escasa población porque eran sumamente incompetentes para el servicio,$^{38}$ no obstante en sus alegatos también aparecían inconsistencias debido a la escasez de efectivos. Tornel reprobó la manera de enganchar gente por parte de las autoridades locales y defendió el sorteo, pero terminó proponiendo:

mañana en la iglesia del convento del Carmen que estaba llena, entraron dos individuos de la comisión de leva o desertores, "armados de punta en blanco" para aprehender a un hombre quien se metió a la sacristía, pero la gente les impidió el paso lo que facilitó su evasión, en “Escándalo en la iglesia del Carmen”, La Sociedad, 9 de mayo de 1858.

35 García (1874). Sobre la percepción de otro médico acerca del reclutamiento forzoso como un medio de coacción que se ensañaba con los sectores más pobres de la población, véase Martínez (1887).

${ }^{36}$ Balbontín (1867, p. 15-17).

37 Facio señalaba que la culpa era de los estados pues no contribuían con el número de hombres que se les solicitaba y comúnmente destinaban a gente “viciosa o inútil”. Insistía además en que se había mandado a las cámaras una iniciativa para el remplazo, y que urgía sacar porque los “cuerpos sufrían muchas bajas en su fuerza...”, Memoria (1831).

38 Memoria (1835). 
Establézcase que a los pueblos que antes del sorteo presentaren desertores les serán rebajados de su cupo; y que verificado el sorteo, todo reemplazo que antes de la $2^{\text {a }}$ revista entregare algún desertor será inmediatamente licenciado. ${ }^{39}$

Independientemente de que se estuviera o no a favor del reclutamiento forzoso lo cierto es que esta clase de métodos coercitivos se pusieron en práctica obligando a los miembros de la sociedad a que participaran ya fuera a través de la delación o captura de desertores, por tal motivo se observa que todo decreto emitido por el delito de deserción iba acompañado de una sección en la que se hablaba del castigo que recibirían aquéllos que encubrían desertores, lo cual sugiere que, a pesar de las sanciones, estos hombres contaron con el apoyo de familiares, amigos o vecinos para evitar ser reintegrados. ${ }^{40}$

Angélica Cacho ha puesto de manifiesto la situación vivida por los desertores quienes podían permanecer impunes durante años, pero la permanencia de los expedientes mantenía "la sombra de la persecución y el castigo"; pues aunque las contiendas armadas y los cambios de administración trastocaban la aplicación de la ley, nunca paralizaron completamente el funcionamiento de las diversos órganos de justicia. ${ }^{41}$

Por lo tanto, así como la autoridad desplegó sus propias estrategias para hacerse de efectivos, a su vez la gente recurrió a varios mecanismos para evadir el sorteo y el servicio militar, y que iban desde tácticas calculadas o

39 Memoria (1835, p. 14, 15).

40 Sin embargo, así como existían las solidaridades también hubo conflictos, y para resolver asuntos de carácter personal la gente utilizó la denuncia como un instrumento de venganza o castigo. Véase el caso de Miguel Rodríguez quien fue acusado por María Josefo Moreno de ser desertor y que además estaba casado con su hija hacía nueve años a quien "le había dado una mala vida...", "Sumaria averiguación contra Miguel Rodríguez acusado de desertor del 1a batallón activo de esta ciudad, 8 de junio de 1835”, AGN, Archivo de Guerra, v. 11, exp. 35. Puede verse también el caso del soldado Eugenio Barrera que andaba por las calles de la ciudad ebrio y armado; unas vecinas al reconocerlo le informaron a su cuñado, Luis Ruiz, quien dio parte al Mayor de la Plaza "temerosos [de que] se desertara...", "Sumaria contra los soldados del regimiento activo de México, Eugenio Barrera y José Santos, acusados de abandono de guardia, 9 de abril de 1844", en AGn, Archivo de Guerra, v. 24, exp. 179. Esta clase de tácticas por parte de los parroquianos o familiares para deshacerse de gente incómoda o como venganza personal fue una práctica común. Para el caso colombiano véase Jurado (2004, p. 673-696).

${ }^{41}$ Cacho (2013, p. 49-60). 
premeditadas, hasta aquéllas que eran improvisadas producto de la desesperación del involucrado, y que a continuación comentaremos.

\section{Sorteados y levantados: entre la exención y el indulto}

Una de las primeras medidas que los hombres pusieron en práctica cuando se llegó a implementar un sorteo era demostrar que estaban exentos de él dado que eran servidores públicos. En el marco del sorteo de 1839 -realizado hasta 1842- la ley señalaba que todos los religiosos, catedráticos, abogados con bufete, médicos y cirujanos, jueces, escribanos, jefes de policía rural y "todos los empleados nombrados por juntas electorales, los dependientes del gobierno general y de los departamentos que tengan título, despacho o algún documento legal de su empleo" estarían exonerados del servicio militar. ${ }^{42}$

Las listas con los nombres de los sorteados se ponían en lugares públicos por ocho días. ${ }^{43} \mathrm{~A}$ partir de ese momento tenían quince días para demostrar sus excepciones legales para ser liberados de la carga, pues el artículo 21 de la ley indicaba que todo vecino tenía derecho a reclamar las omisiones que notara en las listas. ${ }^{44}$ De modo que hombres como don Francisco Cervantes, quien laboraba en la secretaría del Ayuntamiento, no dudaron en llegar a primera hora

$4^{2}$ De la Ley para el sorteo véase el capítulo III llamado "De las excepciones y modo de justificarlas”, en "Sorteo general para reemplazar las bajas del ejército, 26 de enero de 1839", Dublán y Lozano (1876, t. 3, p. 583-585).

43 "Lista de individuos por orden que salieron en los globos, en el sorteo que se verificó el día 9 de abril de 1842", en Archivo Histórico del Distrito Federal (en adelante AHDF), Servicio militar-padrones, v. 3280, exp. 16. "Individuos de las subprefecturas y pueblos del distrito que salieron con la suerte de ser soldados", AHDF, Servicio militar-padrones, v. 3280, exp. 17. El decreto del sorteo militar del 26 de enero de 1839 estipulaba que la lista de empadronados se realizaría en cada manzana de los 32 cuarteles. En "Lista de los ciudadanos solteros empadronados para el sorteo que para reemplazar las bajas del ejército...26 de octubre de 1839", AHDF, Servicio militar-padrones, v. 3280, exp. 4. Véase también "Lista de los ciudadanos viudos sin hijos comprendidos en la primera clase de los que deben entrar al sorteo, con arreglo a lo prevenido en el primer miembro del artículo 14 del Supremo Decreto dado en 26 de enero de 1839", AHDF, Servicio militar-padrones, v. 3280, exp. 5.

44 "Sorteo general para reemplazar las bajas del ejército, 26 de enero de 1839", en Dublán y Lozano, (1876, t. 3, p. 583). 
para ser indultados. ${ }^{45} \mathrm{El} 16$ de abril de 1842 el Prefecto, el secretario y demás personas que presidían la sesión para llevar a cabo un sorteo extraordinario dieron cuenta de que:

Muchos individuos en número de más de doscientos hasta esta hora se han presentado, solicitando se les exceptúe por las causas que alegan, las cuales unos justifican, otros protestan justificar, y otros simplemente alegan, según se ha podido colegir de la lectura de algunas solicitudes, no siendo posible dar cuenta circunstanciadamente con ellas, porque desde las 9 de esta mañana y al momento de instalada la junta, se han estado recibiendo y se están asentando los nombres de los interesados en la respectiva lista. ${ }^{46}$

Aunque se desconoce cuántos hombres dedicados al servicio público fueron eximidos y cuántos no, lo que es cierto es que varios de ellos hicieron uso tanto de documentos legales como epístolas de jefes o conocidos que contaban con un capital social y político que los acreditaba como funcionarios. ${ }^{47} \mathrm{Sin}$ embargo, pocos fueron los que contaban con un empleo en la administración pública que los proveyera de relaciones y vínculos con la autoridad local facilitándoles ser dispensados del reclutamiento.

Estas son sólo algunas de las formas de las que los sorteados se valieron, pero debemos recordar que buena parte de ellos fueron reclutados por la fuerza. Evidentemente quienes implementaban la leva levantaban a cualquier parroquiano sin importar si cumplían o no con los requisitos mínimos. De suerte que al haber sido capturados los afectados escribían a las autoridades para solicitar

45 En AHDF, Militares-padrones, v. 3282, exp. 6. En este volumen existen varios documentos relativos a las excepciones de los empleados de las municipalidades y otras dependencias de gobierno.

${ }^{46}$ En AHDF, Militares-padrones, v. 3282, exp. 9. Para los sorteos efectuados en los días 10, 11, 20 y 21 de abril de 1842, y desde el momento que se instalaba la Junta de Sorteo, "los individuos llamados empezaban a reclamar exenciones”, AHDF, Militares-padrones, v. 3282, exp. 11.

47 También debe tomarse en cuenta la posibilidad de que quienes hayan sido liberados fueran funcionarios públicos con un perfil medio o alto. Llama la atención, por ejemplo, que a Cervantes los miembros del Ayuntamiento se refieren a él como don Francisco lo que denota cierta grado de distinción en la sociedad. AHDF, Militares-padrones, v. 3282, exp. 6. 
su auxilio pues al no tener edad para el servicio, ${ }^{48}$ ser el único sostén de su familia, ${ }^{49} \mathrm{o}$ estar físicamente impedidos, ${ }^{50}$ se estaba cometiendo un agravio a su persona dado que la ley los exceptuaba.

Las peticiones, además de haber sido escritas por los afectados, también fueron elaboradas por los propios familiares lo que posiblemente se utilizó para apelar a la sensibilidad de las autoridades. En ese sentido, cabe destacar que la gran mayoría de las epístolas fueron hechas por mujeres -esposas y madres principalmente- mientras que el resto las rubricaron padres (viejos) o abuelos, es decir, a partir de su condición vulnerable (como mujeres y ancianos) su narrativa solía dar la sensación de inestabilidad e infortunio en caso de que ellos y la familia no pudieran contar con el sostén principal..$^{51}$

48 "José Luis Barela informa al Juzgado de Paz no tener la edad reglamentaria para ingresar a los remplazos del ejército. 1844”, en AHDF, Municipalidades, Tacubaya, Milicia, v. 1, exp. 3 .

49 Véanse los casos de José Librado Martínez y Juan Mendoza quienes solicitaban la exención por tener dependientes familiares (1844), AHDF, Municipalidades, Tacubaya, Milicia, v. 1, exps. 4 y 5 . Incluso ya estando en servicio varios pusieron de manifiesto que tenían familia, lo que obliga a pensar que las autoridades pasaban por alto esta prerrogativa. Véanse "Expediente sobre la solicitud del soldado Matías Orocio García para que se le conmute la pena de presidio [...] aduciendo que se fue porque su padre necesitaba ayuda por ser mayor y achacoso, 18 de mayo de 1840 ", en Archivo Histórico de la Suprema Corte de Justicia de la Nación (en adelante AHSCJN), J-1840-01-23-SCJ-TP- Exp-Mx-1938 e "Hilario Blanco. Expediente sobre indulto de la pena capital que solicita el soldado del batallón activo... 1839", en AHSCJN, J-1838-0203-SCJM-15- Exp-Mx-1267. Hilario argumentó que si la pena se ejecutaba se dejaría a cuatro hijos en la orfandad.

${ }^{50}$ La madre de José María Moctezuma expuso que su hijo estaba parado en la puerta de su casa cuando lo cogieron de leva destinándolo como vago porque no pudo acreditar una capellanía con la cual él se mantenía, y además era epiléptico, 29 de agosto de 1812, en AGN, Justicia, v. 827, exp. 55. Enviar a gente incapacitada era una constante. Véase una carta que envía el jefe de la Plaza Mayor del ejército al Gobernador de México solicitándole que exhortara a prefectos, subprefectos y demás autoridades a que no destinen a gente con deformidad física y conocida, como "los cojos, mancos, gibosos, tuertos del ojo derecho, desdentados, de menos de 61 pulgadas de estatura, o de una figura notablemente irregular... 10 de enero de 1840", en AHDF, Militares-sorteos, v. 3282, exp. 4, f. 88.

${ }^{51}$ Varias de estas solicitudes se pueden encontrar en diversos ramos de repositorios tales como el Archivo General de la Nación, el Archivo Histórico del Distrito Federal, entre otros. Algunos ejemplos son "Expediente sobre el indulto que solicita María Josefa Ruiz en favor de su hijo el soldado del batallón activo de Toluca, Pedro Rodríguez, sentenciado a muerte en consejo de guerra, 30 de junio de 1838”, en AHSCJN, J-1838-07-02-SCJ-TP- Exp-MX-1399 y “Expediente 


\section{Enfermedades y mutilaciones}

Si las autoridades hacían oídos sordos a las solicitudes hechas, entonces los afectados buscaban otras salidas posiblemente más arriesgadas o violentas pero que bien valía la pena explorar. Una alternativa era que, previo a ser reclutado, se recurriera a los galenos para certificar que estaban inhabilitados para el servicio militar. La Revista Médica puntualizaba que la gente tenía conocimiento de que los epilépticos no eran aptos para la carrera de las armas debido a los ataques que presentaban, por lo que prevenía a los médicos a distinguir bien entre quienes la padecían y la simulaban:

Apenas habrá enfermedad que importe tanto conocer en todos sus detalles al médico jurista como la epilepsia, lo cual proviene de ser varias y muy intrincadas las cuestiones administrativas y judiciales a que puede dar lugar esta enfermedad, ya porque la simule alguno para escapar al sorteo militar u obtener una licencia absoluta en el servicio de las armas, ya porque pretexten en su defensa los mayores criminales... ${ }^{2}$

Ahora bien, esto podía funcionar para aquéllos que habían sido notificados y que tenían tiempo para orquestar un plan y evadir el sorteo. Pero para quienes estaban incorporados al servicio existía otra alternativa: infligirse un daño físico y quedar inhabilitado. Aunque no abunda mucha información al respecto, la existente permite inferir que varios lo intentaron. $Y$ es que una vez adentro, las continuas reprimendas por el más mínimo desacato podían ser tan violentas ${ }^{53}$

sobre la solicitud de María Estañón para que se indulte a su hijo Máximo Merodio del a pena de 4 años de obras públicas a que fue condenado por el delito de deserción, 1841", en AHSCJN, J-1841-02-27-SCJ-TP- Exp-Mx-2383.

52 "Lecciones sobre la Epilepsia, considerada bajo el punto de vista de la Medicina legal, dadas en la Escuela de Medicina de México por el profesor del ramo, D. Luis Hidalgo Carpio, los días 20 y 22 de septiembre de 1869", en Gaceta Médica de México, 15 de junio de 1870.

$53 \mathrm{Al}$ respecto véase la carta que hicieron pública los soldados del Batallón de Inválidos en la que denunciaban al teniente Don Pablo González quien había propinado varias "patadas y golpes con los puños" a un soldado que se encontraba atado de manos. "Comunicado", en El Fénix de la Libertad, 7 de julio de 1832. Nueve años más tarde los lectores de El Cosmopolita supieron del indulto otorgado a un soldado de este mismo batallón por haber abandonado la 
que es factible pensar que sentimientos de miedo o ansiedad se apoderaran de reclutas ${ }^{54}$ y soldados, llevándolos a consumar toda clase de imprudencias como la mutilación de algún miembro, práctica bastante socorrida. Tal como ocurrió con Diego de San Juan quien, después de fugarse y seguramente en el entendido de que mandarían una comisión para aprehenderlo, decidió cortarse con un machete cuatro dedos de la mano derecha, de lo cual falleció 20 días después. ${ }^{55}$

$\mathrm{Al}$ parecer someterse a esta clase de medidas radicales era algo acostumbrado, pues la Novísima Recopilación contenía una orden del 9 de febrero de 1796 en la que se mandaba a castigar a todos aquéllos que para "libertarse del servicio se inutilizan maliciosamente" ${ }^{56}$ Para la segunda mitad del siglo XIX estas formas de rehuir el servicio seguían siendo conocidas. El médico Ezequiel Torres refería que una de las prácticas comunes entre los soldados era apoyar la culata del rifle en el suelo y poner la palma de la mano en la boca y darse un tiro. ${ }^{57}$ No obstante, esto no los eximió por completo pues varios fueron enviados al Batallón de Inválidos en donde además de encontrarse soldados retirados, se hallaban también mancos, cojos, tuertos y demás “inútiles”.

guardia. Su defensor expuso que como no se le pagó su sueldo empeñó una "camisa de munición para atender [...] las necesidades de su familia" y a la "hora del reconocimiento de prendas", su sargento advirtió que no traía la camisa y, "temeroso de las resultas de su falta”, el soldado se fugó. El Cosmopolita, 13 de mayo de 1843.

54 El recluta es aquel hombre que estaba en un periodo de instrucción previo a convertirse en soldado.

55 "Sumaria averiguación en Yahualica contra el desertor, Diego de San Juan, sobre la mutilación que se hizo de los dedos para no servir en ejército, falleció. Enero de 1842", en AGN, Archivo de Guerra, v. 89, exp. 948.

${ }^{56}$ Al desertor Diego de San Juan se le iba a procesar a partir de dicha ley. Ibidem. Christian Archer y Juan Marchena han argumentado que en los últimos años del periodo colonial "la epidemia de las deserciones" era generada por diversas razones: reclutamiento forzoso, falta de pago, maltrato de sus superiores, pésimas condiciones de vida en los cuarteles, etc. en Archer (1983, p. 339) y Marchena (1992, p. 244-271). Renuencia que encontraremos también en el México independiente. Al respecto, véanse Costeloe (2000, p. 106, 190, 191, 218, 219, 220, 228-237, 313) y Serrano (1993). Sobre las levas como método de enganche véanse Cacho (2013), Chust (1996) y Serrano (1996).

57 Torres, (1882, p. 18). 


\section{Una vez adentro... momentos, espacios y simulaciones}

Además de haber hombres que desplegaron una serie de estratagemas para impedir su incorporación al ejército, hubo otros que no pudieron eludirlo y terminaron con un arma en la mano, lo que no significó que aceptaran del todo su situación pues, una vez que pasaron de recluta a soldado, hicieron lo posible por escapar pero sin tomar medidas tan drásticas (como la mutilación), sino calculando los momentos y los lugares oportunos para hacerlo.

De acuerdo con la información que aparece en las 111 hojas de filiación tenemos que sólo el 10\% fueron voluntarios y el $63 \%$ habían sido enviados desde diferentes instancias gubernamentales (comandancias generales, Estado Mayor, gobernadores, prefectos políticos, ayuntamientos)..$^{58} \mathrm{Al}$ hacer un aproximado del tiempo que estuvieron en el servicio -desde el día que ingresaron a la compañía hasta el que escaparon- se puede observar que quienes intentaban marcharse inmediatamente eran los menos (Cuadro 1).

A partir de la fecha de entrada de los reclutas podemos observar que únicamente el $5 \%$ escapó del cuartel en menos de un mes, en cambio entre los meses que van del primero al noveno tenemos que el porcentaje de prófugos se elevó hasta un $65 \%$. De acuerdo con las cifras, el tiempo aproximado que estaban los soldados en el ejército antes de desertar era máximo de un año, de tal modo que del décimo mes en adelante el porcentaje de fugas desciende.

Lo anterior tenía una explicación posible. Huir cuando se tenía tan sólo unas horas o escasos días de ser enganchado suponía un fracaso casi seguro puesto que no conocían el lugar al que habían sido destinados ni la gente y podían ser apresado fácilmente, arriesgando incluso su integridad física. Lo mejor era conocer la dinámica cotidiana del cuartel, de tal suerte que decidían permanecer en el lugar y mantener una conducta deferente, mostrar obediencia, ganar la confianza de sus superiores y, tiempo después, escapar con mayor facilidad. Estas fugas se hacían justo cuando soldados, cabos, incluso sargentos, estaban montando guardia o al frente de ella en garitas, establecimientos públicos y oficiales, etcétera.

${ }^{58}$ De $17 \%$ no hay datos, el $4 \%$ venían de otro cuerpo, el $3 \%$ eran reemplazos y el otro $3 \%$ eran desertores. 
Cuadro 1

Periodo aproximado en cometer la defección

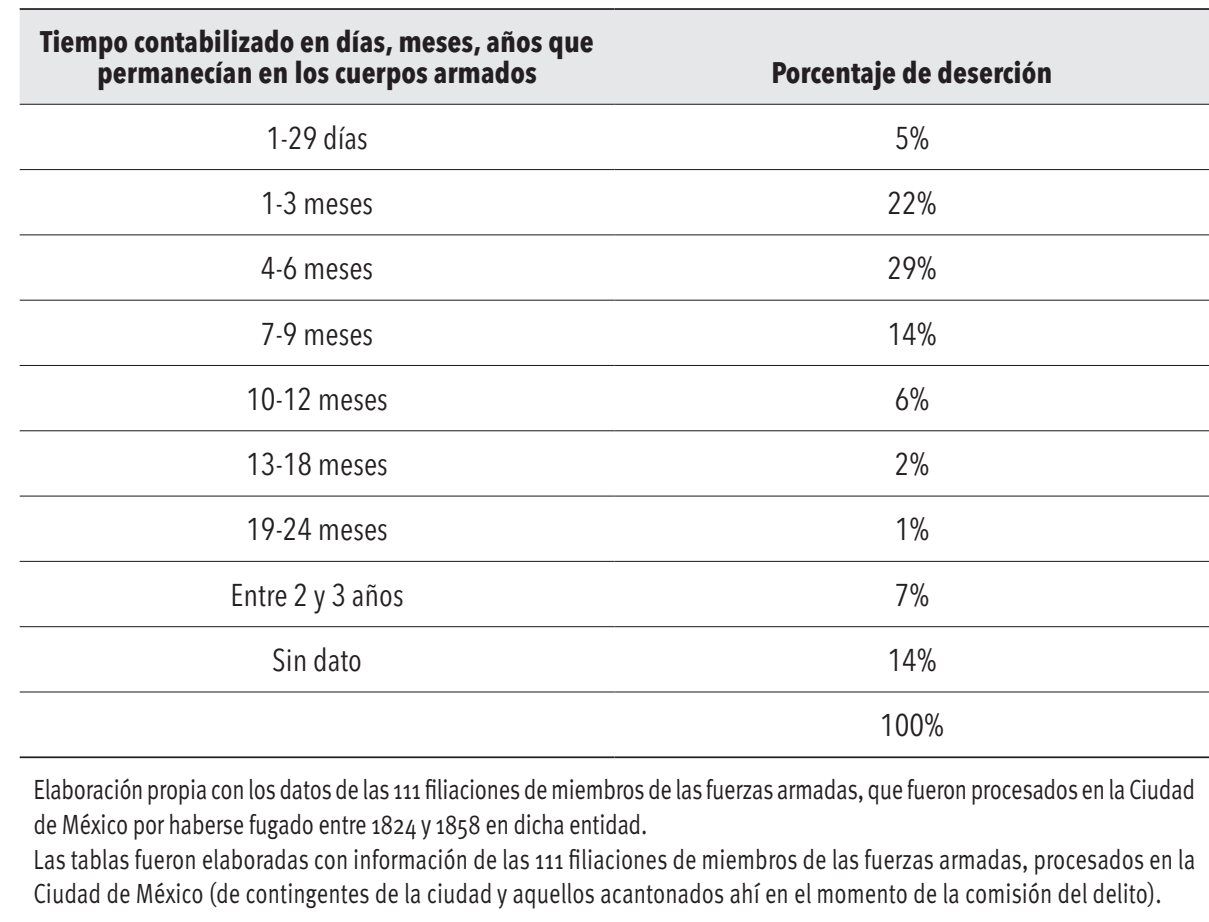

Es decir, durante el tiempo que los conscriptos estuvieron en servicio identificaron cuáles eran las horas de entrada y salida del personal, así como los instantes de calma y bullicio (Cuadro 2), sabían cuáles eran las zonas más o menos vigiladas, etcétera. (Cuadro 3), todo lo cual les brindaba oportunidad para llevar a cabo la defección sin que fueran aprehendidos o, al menos, no en el instante. Tal como lo refiere el caso de Policarpo Herrera que durante los seis meses en el servicio dio muestras de buena conducta, pero se marchó en cuanto lo pusieron de guardia en la esquina de la calle de Moneda, ${ }^{59}$ o el del soldado

59 "Sumaria contra el granadero de la guardia de los supremos poderes Policarpo Herrera, acusado de haber abandonado el puesto de centinela. 12 de enero de 1843", en AGN, Archivo de Guerra, v. 50, exp. 471. 


\section{Cuadro 2}

Momento del día en que se cometió la fuga

\begin{tabular}{cc}
\hline Momento del día & Porcentaje de fugas \\
\hline Mañana & $7 \%$ \\
\hline Tarde & $28 \%$ \\
\hline Noche & $42 \%$ \\
\hline No se sabe & $23 \%$ \\
\hline
\end{tabular}

Elaboración propia.

Se utilizaron los 123 procesos por fugas de los miembros de las fuerzas armadas (citadinos y foráneos que acantonaban en la ciudad al momento de cometer el delito). El estudio original de donde se sacaron las bases de datos enfatizaba el análisis en la tropa: cabos y soldados, por lo cual la mayor parte de los procesos les corresponden a ellos. Todos los casos fueron juzgados en la ciudad de México, de los 123 procesos 92 fueron por abandono de guardia y 31 por deserción; así también los mismos dan cuenta que 106 eran soldados, once cabos, tres sargentos, un alférez, un subteniente y un capitán; 89 de ellos eran miembros del ejército permanente, 17 del activo, 11 inválidos y 6 fueron registrados como "reemplazo". Como mencionamos arriba, los procesos corresponden a los años comprendidos entre 1824 y 1858.

José Barajas quien escapó cuando fue a comprar papel. ${ }^{60}$ Otro más fue el de Antonio Quirino a quien se le comisionó para ir por un tlaco de cigarros a la tienda, y en el acto "se largó". ${ }^{61}$

Los meses recluidos en el cuartel, además de permitirles conocer la vida militar les sirvieron también para hacer y estrechar vínculos con gente que estaba en igual o peor condición que la suya. Estas relaciones se consolidaron aún más tanto por compartir el infortunio de haber sido enviados por la fuerza como tener ciertas afinidades en común, a saber, el oficio, el origen social o territorial, etcétera, configurándose así relaciones solidarias (quizás efímeras) entre aquellos que hallaban los espacios adecuados para conversar acerca de

60 “Contra el soldado del regimiento ligero de infantería, José Barajas, acusado de haber abandonado la guardia de la lotería, 15 de marzo de 1841," en AGN, Archivo de Guerra, v. 24, exp. 188.

${ }^{61}$ Al preguntársele a un soldado que estuvo como testigo de identidad sobre la conducta de Quirino dijo que tenía buena conducta, aunque también aclaró que hacía poco tiempo había salido del calabozo por haber desertado en otra ocasión. "Contra Antonio Quirino, soldado de la $3^{\underline{a}}$ compañía del $2^{0}$ batallón del regimiento de infantería, acusado de haber abandonado la guardia de la prisión de los Naranjos, 13 de mayo de 1840", en AGN, Archivo de Guerra, v. 37, exp. 366. 
Cuadro 3

Lugar donde se cometió la fuga

\begin{tabular}{cc}
\hline Zona & Porcentaje \\
\hline Adentro del cuartel & $11 \%$ \\
\hline En servicio fuera del cuartel $^{\star \star *}$ & $54 \%$ \\
\hline Afuera del cuartel & $7 \%$ \\
\hline Establecimiento comercial & $4 \%$ \\
\hline Sin dato & $24 \%$ \\
\hline
\end{tabular}

Elaboración propia con base en 123 procesos por fuga.

Se refiere a los lugares donde estuvieron de guardia como las garitas, hospitales, oficinas de gobierno, etcétera.

los maltratos, renegar contra sus superiores, incluso, planear fugas en grupo. El 9 de noviembre de 1844, cuatro soldados, tres de ellos originarios de Guadalajara y uno de Zacatecas, fueron destinados para servir por seis años. Después de un par de meses, el oriundo de Zacatecas fue ascendido a cabo, una vez empleado y al mando de sus compañeros, todos emprendieron la huida. ${ }^{62}$

De este proceso conviene resaltar que los soldados sólo tenían cuatro meses en el servicio, y sólo el cabo habilitado, José María Ayala era quien llevaba un año y cinco meses en el ejército. ${ }^{63}$ Asimismo todos se conocieron en el cuerpo de reemplazos y, por lo que consta en las filiaciones, dos de los jaliscienses con oficio de sastre y de labrador fueron enviados de su entidad el mismo día e incorporados a este cuerpo el 9 de agosto de 1844. De lo que se puede inferir que si no se conocían de tiempo atrás, lo hicieron durante el traslado de la cuerda a la ciudad de México. ${ }^{64}$

62 "Proceso instruido contra el cabo José María Ayala y soldados José María Morales, Prudencio Carrisales y José María Aguilera, acusados de abandono de guardia de las armas, el día 9 de noviembre de 1844", en AGN, Archivo de Guerra, v. 1, exp. 3.

${ }^{63}$ Aunque esta fuga del cabo habilitado era la segunda, pues medio año después de su ingreso se había escapado.

64 Véase también el caso de Desiderio Hernández e Isabel Espinoza, ambos habían sido enviados por el gobernador de Guanajuato, se les mandó al mismo cuerpo y escaparon juntos. “Proceso instituido contra el cabo Desiderio Hernández y el cabo Isabel Espinoza del batallón activo de León acusados de haber abandonado la guardia del Hospital de San Pablo el día 15 de agosto del corriente año, 1855", en AGN, Archivo de Guerra, v. 54, exp. 530. 


\section{Cosechando la confianza y aprovechando la necesidad}

Como hemos podido dar cuenta, varios soldados disimularon o desplegaron conductas deferentes frente a la autoridad, mismas que sirvieron como mecanismos para -más allá de la relación de carácter formal que tenía un soldado y su superior- establecer relaciones "informales" dando paso a que los jefes otorgaran un voto de confianza a sus subordinados, pues sólo así, éstos últimos podrían llevar a cabo la defección. Ahora bien, aunque un superior sin necesidad de vínculo personal y sólo por el hecho de ser jefe podía asignar determinadas tareas al soldado, lo cierto es que algunas de éstas eran ajenas a las obligaciones de su oficio, por ejemplo, ir a comprar tabaco o comida.

Las situaciones exhibidas tanto en la prensa como en los sumarios apuntalan los argumentos acerca de los vínculos informales que soldados y jefes inmediatos establecían. Una muestra de lo anterior lo ofrece El Siglo XIX:

Antenoche como a las once y media en uno de los portales había una acalorada discusión entre varios soldados borrachos. Uno de ellos decía que era cabo y en el uso de su autoridad había quitado a otro la camisa, y cuatro pesos. Algunos de los soldados sostenían que esto era abusar de la superior graduación; pero el cabo, recomendando la subordinación y la disciplina, insistía en conservar la camisa y los cuatro pesos, diciendo que lo acusaran ante autoridad competente. En esto llegó un caballero a quien todos llamaron mi jefe, quien probablemente arreglaría la cuestión. ${ }^{65}$

Pero si mantener conductas deferentes o buscar la "amistad informal" de los superiores no garantizaba una posible fuga, había otro recurso que podía utilizarse: esperar pacientemente el voto de confianza para ser enviado a la calle en alguna comisión o incluso conseguir un ascenso temporal como "cabo

65 “La autoridad de un cabo", en El Siglo XIX, 16 de marzo de 1853. Otro botón de muestra es el proceso contra Pantaleón Balderas quien aprovechó para abandonar la guardia cuando su jefe inmediato le dio permiso para comer en el tendejón de enfrente del cuartel, y después ir a tomar a la pulquería de la esquina. "Sumaria contra el soldado de la compañía del regimiento ligero de caballería, Pantaleón Balderas, acusado de haber abandonado la guardia de prevención. 26 de mayo de 1841", en AGN, Archivo de guerra, v. 25, exp. 192. 
habilitado". Éste era el jefe inmediato del soldado. De acuerdo con la ordenanza militar los soldados podían ascender a cabos siempre y cuando cumplieran con ciertos requisitos: leer, escribir y conocer tanto las obligaciones de cada uno de los grados militares como los castigos a los que se hacían acreedores en caso de desobediencia ${ }^{66}$ Aunque la legislación no precisa el tiempo que debía pasar para ser promocionado, se deduce que para familiarizarse con la dinámica y la logística de la institución se tenía que permanecer en el ejército, por lo menos, un par de meses. Sin embargo, habría que decir que este grado, las más de las veces, no se dio por el mérito del soldado sino por una "urgente necesidad" de efectivos, lo cual tenía como telón de fondo el problema de las defecciones.

Por los sumarios se observa que quienes ascendieron rápidamente fueron nombrados "cabos habilitados", cargo "temporal" que no aparecía en la ordenanza militar y que, al parecer, fue implementado de manera informal por las autoridades como un paliativo dada la escasez de hombres que pudieran fungir como jefes inmediatos, ello sin importar que en el servicio llevaran días o un mes. Situación que bien pudo ser concebida por los soldados como una oportunidad para "largarse".

Los ministros de Guerra, José Antonio Facio (1831) y José Joaquín Herrera (1834) indicaron que, dado el número creciente de deserciones, la mayoría de los cuerpos armados estaban incompletos. Herrera explicaba que el ejército estaba en un periodo de plena desmoralización e indisciplina debido a los trastornos políticos y sociales ocurridos en ese año, asegurando que de los batallones del interior que estaban en armas -entre ellos el primero y el segundo de México- "no puede formarse un solo cuerpo por la falta de gente que lo reemplace". ${ }^{67}$ Coyunturas como éstas fueron recurrentes y por ese motivo llegaron a poner gente con poca experiencia en puestos “clave”, favoreciendo una situación que reclutas y soldados supieron capitalizar cuando se les ponía como cabos habilitados. ${ }^{68}$

\footnotetext{
66 Véase “Título II. Del cabo, art. 3”, en Ordenanza (1833, p. 73).

67 Memoria (1834).

68 Para 1853, año convulso tanto como la misma década, se dispuso que todo aquel vago que tuviera cualidades para el servicio militar debía ser arrestado y consignado a la comandancia general para su alistamiento. "Ley para corregir la vagancia”, 20 de agosto de 1853, en Dublán y Lozano, (1876, t. 6). "Sobre que los vagos se apliquen al servicio de armas", 18 de
} 
Ejemplo de lo anterior es el proceso hecho contra el cabo Gumersindo Salas quien escapó del presidio de Santiago Tlatelolco el 5 de diciembre de 1854, junto con otros soldados que estaban de guardia bajo sus órdenes. En su hoja de filiación se indica que Salas ingresó en julio de ese mismo año, ascendió a cabo en noviembre y desertó en diciembre, es decir, llevaba cinco meses en el ejército y únicamente un mes como jefe inmediato de los soldados cuando huyó. ${ }^{69}$ Otro sumario que iba en el mismo tenor era el de los cabos Desiderio Hernández e Isabel Espinoza quienes entraron el 1 de julio de 1855, se les ascendió quince días después y al cabo de un mes abandonaron la guardia del Hospital de San Pablo.70

En otra causa instruida contra Jesús Bernal y Pascual Pedro, el cabo Agustín López declaró que el sargento le había ordenado poner al soldado Bernal al frente de dos mancuernas de presos porque era "soldado de los viejos y por consiguiente de confianza...". ${ }^{71}$ En efecto, el soldado llevaba año y dos meses en el ejército razón por la cual se le consideró “soldado viejo”, pero al mirar la filiación se revelan más cosas que el fiscal no tomó en cuenta. Bernal había entrado al servicio el 23 de marzo de 1843 y para el 15 de agosto había desertado. No obstante, se le aprehendió 20 días después; a pesar de su delito se le volvió a poner en activo y, nuevamente, desertó. Esto obliga a pensar si en verdad el sargento le tenía plena confianza, o desconocía la defección anterior del indiciado, o simplemente dedujo que conocía las funciones de cabo dado que él, a diferencia del resto de sus compañeros, era quien tenía más tiempo en el ejército. Otro botón de muestra de que las compañías nunca estaban completas lo

octubre de 1853, en ibidem. Ambas leyes indican la urgencia de hombres en las compañías militares de diversas partes del país.

69 "Sumaria averiguación contra el cabo y soldados del batallón de guías de infantería ligera, Gumersindo Salas, Pedro Candelario, José Pablo y José Juan, acusados de haber abandonado la guardia del presidio de Santiago. 1854", en AGN, Archivo de Guerra, v. 54, exp. 527. Un subteniente declaró que tenía sospecha de que el cabo indujo a los demás a escapar.

70 “Proceso instituido contra el cabo Desiderio Hernández y el cabo Isabel Espinoza del batallón activo de León acusados de haber abandonado la guardia del Hospital de San Pablo el día 15 de agosto del corriente año, 1855", en AGN, Archivo de Guerra, v. 54, exp. 530.

${ }^{71}$ El juicio quedó suspendido porque Bernal no apareció. "Proceso instruido contra los soldados del batallón fijo de México Jesús Bernal y Pascual Pedro acusados de haberse fugado con sus mancuernas de presos llevándose el armamento el 27 de mayo de 1844", en AGN, Archivo de Guerra, v. 24, exp. 184. 
encontramos en este mismo expediente. Cuando el fiscal le preguntó al cabo sobre los nombres de "las mancuernas fugadas" y el de los soldados que se hallaban en servicio junto con el habilitado Bernal, mencionó que sólo recordaba el de los soldados: María Sordia, José Serapio, Santiago Vázquez y Desiderio Guerrilla, y de los cuatro los dos últimos se hallaban "desertados".

Si volvemos al cuadro 1 y tomamos en cuenta que cuando más se consumaba la defección era entre el primero y el noveno mes (65\%), es lógico pensar que la institución tuviera una dificultad para formar soldados profesionales con conocimiento suficiente de la vida militar para ser promocionados, toda vez que el periodo de formación y aprendizaje era justo en el que escapaban. Al revisar los juicios hechos contra los cabos se observa que su ascenso se dio con tan sólo poco tiempo de estar en servicio, y no sólo eso sino que además varios no cumplían con algunos de los requisitos establecidos en la legislación (no sabían firmar y es probable que tampoco supieran escribir). Durante un proceso hecho contra unos soldados por abandono de guardia, y al preguntársele al cabo Telésforo González que si el parte militar que se leía era suyo, dijo que era el mismo que había entregado en la plaza pero que "se lo puso el tendero de la esquina por no saber escribir". ${ }^{72}$

De los 123 procesos revisados tenemos que once fueron hechos contra cabos de los cuales siete no sabían firmar. ${ }^{73}$ De ellos, cinco se fugaron cuando tenían entre uno y tres meses, dos a los cuatro y seis meses, tres lo hicieron después del año y sólo de uno se desconoce cuándo se marchó. Respecto de aquéllos que escaparon después del año y que, claro está, eran los que llevaban más tiempo en el ejército no se tienen las filiaciones de los cuerpos en los que habían estado anteriormente y sólo brindan información de la última compañía en la que estaban cuando cometieron el delito. En cambio existen otras hojas de servicio (las menos) que sí hacen un resumen o recuento del desempeño profesional del soldado. Así por ejemplo, en una hoja de filiación incluida en la averiguación contra un cabo por defección, se observa que no era la primera vez que se

72 “Sumaria averiguación contra los soldados del 6ํ regimiento de infantería, Antonio Pliego y José Hilario Chavarría y Mariano Paredes, acusados de haber abandonado la guardia de extranjeros, el 6 de noviembre de 1839", en AGN, Archivo de Guerra, v. 12, exp. 98.

73 También contamos con los procesos de cuatro sargentos de los cuales sólo dos rubricaron. 
marchaba, ya que había desertado dos veces más. De igual forma, se debe advertir que existen juicios que se abrieron contra soldados que abandonaron la guardia o desertaron en calidad de "cabos habilitados", pero como fueron consignados como soldados da la impresión de que los cabos desertaban menos, lo cual es cuestionable.

Así pues, la necesidad continua de hombres hizo que las autoridades militares pasaran por alto lo estipulado en la legislación. ${ }^{74}$ Para quienes estaban a disgusto en el servicio o habían sido enviados por la fuerza esta "excepción" a la regla o "debilidad institucional" les brindó las argucias legales para disminuir la pena o evitar el castigo. En el juicio contra José María Ayala, comentado anteriormente, conviene detenerse en algunos datos reveladores que el sumario desvela. El soldado fue enviado por el gobernador de su estado, suponemos que como forzado dado que en las hojas de filiación aparecía si eran voluntarios. Entró al cuerpo de reemplazos el 14 de julio, ascendió como cabo el 19 de agosto, y desertó tres meses y medio más tarde. Pero el asunto no quedó ahí, el 14 de enero de 1844 se "presentó” en Querétaro volviéndosele a ascender el 1 de octubre de ese mismo año; Ayala escapó de nueva cuenta el 5 de noviembre. ${ }^{75}$ Juicios como este dan cuenta de que aunque las autoridades tenían conocimiento de que los indiciados habían cometido otros delitos militares, éstos no fueron tomados en cuenta o se decidió pasarlos por alto, en buena medida por la falta de recursos humanos; bien valdría la pena preguntarnos qué tan frecuente fue esta situación.

74 "Expediente sobre indulto que solicitan los soldados del $8^{0}$ regimiento de infantería, Francisco Ortega y Prisciliano López, octubre 1839”, en AHSCJN, J-1839-09-18-SCJ-TP- ExpMx-1651. Ambos soldados debían ser pasados al paredón pero se consideró, por una "especie de utilidad y servicio público", que fueran indultados y pasaran al batallón fijo de Veracruz porque además ya estaban "aclimatados en aquel mortífero temperamento, y ser útil y conveniente que aquel cuerpo se halla en la fuerza que debe tener..." El fiscal argumentó además que el consejo de guerra que los sentenció no tomó en cuenta que sólo llevaban 22 días de haber sentado plaza.

75 En este expediente aparece la declaración de un sargento quien argumentó que aquella noche, además del cabo de plaza José María Ayala, estaban otros dos "soldados habilitados" pero que ya no se encontraban en su cuerpo sino en el ligero de caballería. "Proceso instruido contra el cabo José María Ayala y soldados José María Morales, Prudencio Carrisales y José María Aguilera, acusados de abandono de guardia con armas, el día 5 de noviembre del mismo año y comenzó el día 9 de noviembre de 1844”, en AGN, Archivo de Guerra, v. 1, exp. 3. 
Dadas las circunstancias y al no aplicar la norma a pie juntillas las autoridades abrieron la posibilidad de que los indiciados, frente a un proceso en su contra, articularan un discurso en el que anteponían la ingenuidad e ignorancia de su persona, echando mano de la ordenanza militar y poniéndola a su favor. ${ }^{76}$ Sirva de muestra el juicio de Vicente Aguilar que, en julio de 1844, fue designado cabo habilitado para cuidar de los centinelas que resguardaban el cuartel, pero después de la oración de la noche, intentó escapar. En el expediente aparecen cuatro declaraciones y todas refieren que Aguilar, en los cuatro meses que llevaba en el cuerpo de reemplazos tenía buena conducta, ya que nunca había faltado ni extraviado prenda alguna. No obstante, su abogado defensor, Justo Montenegro, teniente de la $2^{\mathrm{a}}$ compañía de infantería del mismo cuerpo, evidenciaba la realidad que prevalecía en el ejército:

Acreditado más a favor de mi ahijado que prueba su honradez y dedicación en el servicio de las armas que en el limitado discurrir que cuenta de soldado fue nombrado. Aunque contra el orden para desempeñar las funciones de cabo sin tener presente todas las circunstancias que se requieren para estos casos, a falta de cabos de plaza para elegir al soldado de más aptitud, conocimientos y circunspección de lo que carece mi defendido así por la poca practica en las funciones de este delicado empleo, como por ser su configuración de un joven que su misma edad [18 años] no requiere todavía la representación de un inmediato jefe de los soldados, y para mejor decir de la instrucción tan interesante para el gobierno de la tropa. ${ }^{77}$

Otro sumario que va en el mismo sentido que el anterior es el de Alvino de la Cruz, soldado de caballería del regimiento permanente, quien se fugó con sólo llevar un mes en el ejército. En su declaración el ayudante del regimiento don Fernando Nieva dio cuenta de lo pragmáticas que podían ser las autoridades dada la escasez de efectivos, pero retratando también la condición que se vivía

${ }^{76}$ Evidentemente atrás de ellos se encontraba su abogado defensor.

77 Vicente llevaba seis meses y medio en el calabozo del cuartel. "Proceso instruido contra Vicente Aguilar soldado del cuerpo de reemplazos, acusado de abandono de guardia el 7 de noviembre de 1844", en AGN, Archivo de Guerra, v. 1, exp. 5. 
en los cuarteles sin jefes inmediatos, con patrullas improvisadas por reclutas y no soldados, quienes la mayoría de las veces habían sido enviados por la fuerza y, además, sufrían el abuso de sus jefes:

Que en su guardia no había sargento y nada más el cabo que lleva citado a causa de que el regimiento se hallaba fuera de la capital y en ella sólo había quedado un piquete del que la mayor parte eran reclutas... Que no sabe si en su compañía le leyeron las leyes penales que respecto del prest y vestuario le ha recibido lo mismo que a los demás... que la revista de comisario la pasó el mes de mayo por papeleta y no los meses anteriores por ser recluta, cuya causa no se le nombraba ningún servicio y que sólo la necesidad de no haber fuerza que pudiera nombrarse de guardia para cuidar el cuartel hizo que se nombrara servicio al soldado Cruz no obstante no tener el tiempo ni la instrucción necesaria para aquello; que cree que el motivo por lo que desertó fue el que habiendo sido destinado por la autoridad civil para servir en su cuerpo, y como era recluta, según manifestado no se dejaba salir a la calle y por esto cree el que declara abandono la guardia... ${ }^{78}$

De igual modo, el fiscal argumentó que como Alvino fue enviado por la autoridad política de Tulancingo y con sólo un mes y siete días en la compañía, "periodo tan corto [...] no es suficiente para que haya podido imponerse de sus obligaciones, ni menos de la leyes penales a que estaba sujeto", por lo que el caso se suspendió hasta que se presentara o fuera aprehendido, y se le sancionara por el delito de deserción simple. ${ }^{79}$

78 “Proceso instruido contra el soldado de la 2ª compañía del 1 er regimiento de caballería permanente, Alvino de la Cruz, acusado de haber abandonado la guardia de prevención de su cuartel saltando las tapias el 21 de mayo de 1852 comenzando su causa en 6 de junio de 1853 ", en AGN, Archivo de Guerra, v. 192, exp. 1928.

79 Algo que es de notar en este caso es que Alvino su fugó el 21 de mayo de 1852 pero los edictos en los que se le solicitaba a comparecer al cuartel de Peralvillo se emitieron hasta el 6 de septiembre de 1853 (un año después del delito). Se desconoce si existieron decretos anteriores o si, durante esos quince meses, la autoridad militar tenía conocimiento pero no hizo nada al respecto. De igual modo llama la atención que el 26 de septiembre de 1853 se decretara la “Ley penal para los desertores, faltistas, viciosos del ejército, así soldados como a los oficiales: juicio y modo de imponer las penas y castigos a los que encubran o auxilien la deserción” 
Otro juicio parecido fue el del soldado Felipe Amilpa acusado de abandono de guardia junto con un cabo. Su abogado expuso que el recluta llevaba 40 días en servicio, no había prestado juramento de fidelidad a su bandera, en consecuencia, preguntaba:

¿[Serán] suficientes cuarenta días para inculcar a un hombre vulgar las afecciones por la carrera todos los deberes de un soldado? Es innegable que hombres de un entorpecimiento moral, hijo de una descuidada educación para comprender lo que se les lee necesitan el tiempo y la frecuente vista de ejemplares castigos, pues desgraciadamente el temor y no la persuasión es quien obra en gentes cuyas primordiales ideas fueron marcadas con un sello de ignorancia..." ${ }^{\prime \prime}$

Razón por la que solicitaba que el delito se considerara como deserción simple y no como abandono de guardia, ya que acusarlo de deserción implicaba enviarlo a las compañías de disciplina, en cambio la sanción por abandono dependería de las circunstancias del caso y posiblemente el abogado pretendía una pena ejemplar. Sin embargo, se solicitaron nuevas diligencias porque no quedaba claro si él y el cabo abandonaron la guardia o desertaron y tampoco si se les había leído o no las leyes penales. Finalmente el juicio se suspendió.

\section{A manera de conclusión}

Una vez consumada la guerra de independencia la sociedad del México independiente estuvo lejos de vivir en paz. Además de ser testigos de crisis políticas y económicas los pobladores se vieron envueltos en conflictos armados a través de la conscripción que, la mayoría de las veces, era de manera forzada. Esta clase de reclutamientos básicamente se llevaron a cabo por la continua

Dublán y Lozano, (1876, t. 6, p. 686-696). Aunque para el 15 de octubre de 1855 hubo un indulto y gente que desertó desde 1853 fue beneficiada con este decreto.

80 “Proceso instruido contra el cabo y soldado del 14ํㅡ batallón de línea José Mendoza y Felipe Amilpa acusados de abandonar la guardia del cuartel de San Agustín la noche del 24 de julio de 1854", en AGN, Archivo de Guerra, v. 61, exp. 607. 
necesidad del ejército para llenar sus filas y tener efectivos con que responder frente a las amenazas del exterior, así como a las rebeliones civiles o militares que se presentaban en diversas partes del territorio.

A pesar de que la ordenanza militar indicaba a los soldados el apego a los principios de "sumisión absoluta y obediencia pasiva", ${ }^{81}$ todo indica que lo que más prevaleció fue la renuencia de la población masculina a servir en el ejército. La aproximación a las prácticas regulares e irregulares (sorteo y leva) para el reclutamiento nos ha permitido dar cuenta de que la gente, una vez incorporada no se quedaba de manos cruzadas ante el futuro que le esperaba, por el contrario, lo que observamos es el despliegue de varias formas de resistencia.

Un primer recurso que se puso en práctica fueron las esquelas a través de las cuales se explicaba los motivos -justos y legales- para ser exentos del servicio, incluso, denunciando las injusticias que cometían algunas autoridades. Las cartas o epístolas para la exoneración fueron utilizadas no sólo como un recurso estratégico por parte de los afectados sino también por sus familiares quienes exponían que sus hijos, hermanos, nietos o esposos eran los que los mantenían y sin ellos caerían en el abandono y la miseria.

Otro recurso menos visto en las fuentes pero que también se utilizó, fue la simulación de una enfermedad o la mutilación de algún miembro; lo que nos habla de la posibilidad más que real de que algunos hombres no estaban dispuestos a soportar una vida en la que padecían hambre, malos tratos y, por si fuera poco, sueldos precarios.

A través de la deferencia y el disimulo algunos hombres se ganaron la confianza de sus superiores esperando el momento de alguna comisión para salir, u obtener un ascenso temporal por el cual pasaban de soldado a cabo (habilitación); de esa forma y sin tanta vigilancia a cuestas, después de un tiempo lograron escapar. Ambas, consideramos, son otras dos tácticas que revelan la inconformidad de servir en la carrera de las armas.

Hemos dado cuenta de algunas formas cómo estos hombres lograron resistir su incorporación y estadía en el ejército; desvelar estos mecanismos

${ }^{81}$ José María Luis Mora apuntaba que las ordenanzas militares habían sido pensadas para crear una clase de hombres armados con base en dichos principios. Mora (1986, p. 268). Al respecto, véase también Gómez (1854). 
permite comprender mejor tanto el impacto de dichas prácticas en la dinámica institucional, así como el proceso histórico de las fuerzas armadas desde la óptica de lo social.

Fuentes

Archivos

Archivo General de la Nación (AGN)

Archivo Histórico del Distrito Federal (AHDF)

Archivo Histórico de la Suprema Corte de Justicia de la Nación (AHSCJN)

Hemerografía

Diario de Avisos

El Cosmopolita

El Fénix de la Libertad

El Siglo XIX

Gaceta Médica de México

La Sociedad

Bibliografía

Aillón SoRIA, E. (2001). "Moralizar por la fuerza. El decreto de reformulación del Tribunal de vagos de la ciudad de México, 1845”, en C. Lida y S. Pérez. Trabajo, ocio y coacción. Trabajadores urbanos en México y Guatemala en el siglo XIX. (p. 86-96) México: Universidad Autónoma Metropolitana/ Porrúa.

Apéndice al tomo primero de la recopilación de leyes, decretos, circulares, reglamentos y disposiciones expedidos por la Secretaria de Guerra y Marina, $\mathrm{s} / \mathrm{f}$, (tomo 1 de los años 1821 a 1891).

ARcher, C. I. (1983). El ejército en el México borbónico, 1760-1820. México: Fondo de Cultura Económica. 
Balbontín, M. (1867). Apuntes sobre un sistema militar para la República. México: Imprenta de Ignacio Cumplido.

Burke, P. (1997). Historia y teoría social. México: Instituto de Investigaciones Dr. José María Luis Mora.

Bustamante C. M. de (2003). Diario Histórico de México, 1822-1834, disco compacto editado por J. Z. Vázquez y H. C. Hernández Silva. México: Centro de Investigaciones y Estudios en Antropología Social/El Colegio de México, v. II.

Cacho Torres, A. M. (2013). "Entre la utilidad y la coerción. Los desertores: una compleja realidad del México independiente (1820-1842)”. Estudios de Historia Moderna y Contemporánea, 45, p. 31-68.

Ceja Andrade, C. (2013). La fragilidad de las armas. Conflicto y vida social entre los militares de la ciudad de México, 1821-186o. Tesis para obtener el grado de doctora en Historia. México: El Colegio de México.

Ceja Andrade, C. (2015). "Algunas consideraciones sobre la presencia de las mujeres en los ejércitos mexicanos durante el siglo xıx”. C. Landa y O. Ávila, Compendios de estudios históricos de la región I (p. 306-331). México: Universidad Autónoma de Querétaro.

Ceja Andrade, C. (2018). "Una mirada a las fuerzas armadas de la ciudad de México a través de las hojas de filiación y los procesos militares, 18241859”, Tzintzun. Revista de Estudios Históricos. 18.

Chust, M. (2005). "Milicia, milicias y milicianos: nacionales y cívicos en la formación del estado-nación mexicano, 1812-1835”, en J. Ortiz Escamilla (coord.). Fuerzas militares en Iberoamérica siglos XVIII y XIX (p. 179-197), México: El Colegio de México/El Colegio de Michoacán/Universidad Veracruzana.

Chust, M. (1996). Sociedad, cultura y ocio en la ciudad de México Independiente, 1821-1830. Anuario de Estudio Urbanos, n. 3, p. 15-33.

Costeloe, M. P. (2000). La República central en México, 1836-1846. "Hombres de bien” en la época de Santa Anna. México: Fondo de Cultura Económica.

Dublán, M. y J. M. Lozano (1876). Legislación mexicana o colección completa de las disposiciones legislativas expedidas desde la Independencia de la República, México: Imprenta del Comercio, t. 3 y t. 6. 
García Figueroa, A. (1874). Higiene militar. Causas de la frecuencia de la sífilis en el ejército y medios de disimularla. Tesis de medicina. México: Imprenta de Ignacio Escalante, bajo de San Agustín, n. 1.

Gómez de la Cortina, J. (1854). Cartilla moral militar. México: Imprenta de Ignacio Cumplido, calle de los rebeldes, n. 12.

HeRnÁNDEZ CháVEZ, A. (2007). "La Guardia Nacional en la construcción del orden republicano”, en M. Chust y J. Marchena (eds.), Las armas de la nación. Independencia y ciudadanía en Hispanoamérica (1750-1850). Madrid: Iberoamericana, p. 223-246.

HERNÁNDEZ LóPEZ, C. (2001). Militares conservadores en la reforma y el segundo imperio (1857-1867). Tesis de doctor en Historia. México: El Colegio de México.

HERNÁNDEZ LóPEZ, C. (2006). “Espíritu de cuerpo' y el papel del ejército permanente en el surgimiento del Estado-nación”. Ulúa. Revista de Historia, Sociedad y Cultura, n. 8, p. 129-154.

JuRAdo Jurado, J. C. (2004). "Soldados, pobres y reclutas en las guerras civiles colombianas". Revista de Indias, n. 232, p. 673-696.

KAHLE, G. (1997). El ejército y la formación del Estado en los comienzos de la independencia de México. México: Fondo de Cultura Económica.

Martínez Calleja, F. (1887). Ligeras consideraciones médicas sobre el ejército. Tesis de medicina, México: Tipografía de El Socialista, Escalerillas 11 y 14. Marchena, J. y M. Chust (2007). Por la fuerza de las armas. Ejército e independencias en Iberoamérica. Castellón: Universidad Jaume I.

Marchena, J. (1992). Ejército y milicias en el mundo colonial americano. Madrid: Fundación MAPFRE.

Memoria del Secretario de Estado y del despacho de guerra y marina leída a las cámaras del congreso general mexicano en marzo de 1835. México: Impresa en abril del mismo año por Ignacio Cumplido.

Memoria del secretario de estado y del despacho de la guerra leída en la cámara de diputados el día 11 de abril de 1834, y en la de senadores el día 12 del mismo, México: Imprenta del Águila, dirigida por José Ximeno, calle de Medinas, n. 6, 1834. 
Memoria del secretario de estado y del despacho de la guerra, presentada a las cámaras el día 24 de enero de 1831, México: Imprenta del Águila, dirigida por José Ximeno, calle de las Medinas, n. 6.

Mora, J. M. L. (1986). Obras completas. Obra histórica I, México y sus revoluciones. v. 4. México: Consejo Nacional para la Cultura y las Artes/Instituto Mora.

Ortiz Escamilla, J. (1988). "El pronunciamiento militar federalista de Gordiano Guzmán, 1837-1842”. Historia Mexicana, v. 38, p. 241-281.

Ortiz Escamilla, J. (1991). "Las fuerzas militares y el proyecto de Estado en México, 1767-1835”, en A. Hernández Chávez y M. Miño Grijalva (comp.), Cincuenta años de historia en México, (p. 261-282.), v. 2. México: El Colegio de México.

Ortiz Escamilla, J. (1999). "Entre la lealtad y el patriotismo. Los criollos al poder”, en B. Connaughton, C. Illades y S. Pérez Toledo, Construcción de la legitimidad política en México en el Siglo XIX (p. 107-126). México: El Colegio de Michoacán/Universidad Autónoma Metropolitana/Universidad Nacional Autónoma de México/El Colegio de México.

Ortiz Escamilla, J. (2005). "Los militares veracruzanos al servicio de la nación”, en J. Ortiz Escamilla (ed.), Fuerzas militares en Iberoamérica, siglos XVIII y XIX (p. 255-270). México: El Colegio de México/El Colegio de Michoacán/ Universidad Veracruzana.

Ortiz Escamilla, J. (2007). "La nacionalización de las fuerzas armadas", en M. Chust y J. Marchena (eds.), Las armas de la nación. Independencia y ciudadanía en Hispanoamérica (1750-1850) (p. 291-323). Madrid: Iberoamericana.

Ordenanza Militar, para el régimen, disciplina, subordinación y servicio del ejército (1833). México: Imprenta Galván.

Pérez Toledo, S. (2008). "El ejército en la ciudad de México a mediados del siglo xIx: datos y reflexiones acerca de su composición social”, en J. E. Rodríguez, Las nuevas naciones: España y México 180o-1850 (p. 315-336). Madrid: Editorial MAPFRE.

Serrano Ortega, J. A. (1993). El contingente de sangre. Los gobiernos estatales y departamentales y los métodos de reclutamiento del ejército permanente 
mexicano, 1824-1844. México: Instituto Nacional de Antropología e Historia.

Serrano Ortega, J. A. (1996). "Levas, tribunal de vagos y ayuntamiento: La ciudad de México, 1825-1836”, en C. Illades y A. Rodríguez Kuri, Instituciones y ciudad. Ocho ensayos históricos sobre la ciudad de México (p. 131-154). México: Sociedad Nacional de Estudios Regionales/UníoS.

SERRANo ORTEGA, J. A. (2001). Jerarquía territorial y transición política. México: El Colegio de Michoacán/Instituto de Investigaciones Dr. José María Luis Mora.

Teitelbaum, V. (2001). "La corrección de la vagancia. Trabajo, honor y solidaridades en la ciudad de México, 1845-1853”, en C. Lida y S. Pérez Toledo (comps.), Trabajo, ocio y coacción. Trabajadores urbanos en México y Guatemala en el siglo XIX (p. 115-156). México: Miguel Ángel Porrúa/Universidad Autónoma Metropolitana Iztapalapa.

Teitelbaum, V. (2008). Entre el control y la movilización. Trabajo, honor y solidaridades artesanales en la ciudad de México a mediados del siglo XIX. México: El Colegio de México.

TORRES, E. (1882). Sobre la 'zona de escoriación' producida en las heridas por armas de fuego. México: Tipografía y Litografía de Gregorio Horcasitas.

VÁzqueZ, J.Z. (1984). "El ejército: Un dilema del gobierno mexicano, 1841-1846", en Problemas de la formación del Estado y la Nación en Hispanoamérica, (p. 319-338). Viena: AHLAV Verlag.

VÁzquEZ, J. Z. (2005). "Reflexiones sobre el ejército y la fundación del ejército mexicano", en J. Ortiz Escamilla (ed.), Fuerzas militares en Iberoamérica, siglos XVIII y XIX (p. 219-232). México: El Colegio de México/El Colegio de Michoacán/Universidad Veracruzana. 